\title{
Random regression analysis of milk yield and milk composition in the first and second lactations of Murciano-Granadina goats
}

\author{
A. Menéndez-Buxadera, ${ }^{*}$ A. Molina, ${ }^{*}$ F. Arrebola, $†$ M. J. Gil,‡ and J. M. Serradilla $\S^{1}$ \\ *Department of Genetics, University of Córdoba, 14071 Córdoba, Spain \\ †Research and Agrarian Training Centre, IFAPA, 14270 Hinojosa del Duque, Córdoba, Spain \\ ¥Cooperativa del Valle de los Pedroches (COVAP), 14400 Pozoblanco, Córdoba, Spain \\ $\S$ Department of Animal Production, University of Córdoba, 14071 Córdoba, Spain
}

\begin{abstract}
Records from the milk recording scheme of Spanish Murciano-Granadina goats were studied to estimate genetic (co)variance components and breeding values throughout the first and second lactations. The data used consisted of 49,696 monthly test-day records of milk (MY), protein (PY), fat (FY), and dry matter (DMY) yields from 5,163 goats, distributed in 20 herds, offspring of 2,086 does and 206 bucks. These records were analyzed by 2-trait random regression models (RRM) and a repeatability test-day model (RTDM). At the middle of lactation, heritability estimates for MY, DMY, and FY obtained with RTDM were larger than those estimated with RRM, and the opposite was true for PY. The RRM estimates of heritability for MY, FY, and PY were very similar throughout the trajectories of both lactations. Heritability estimates for DMY decreased through the lactation period. The genetic correlations between the first and second lactation records estimated for all traits by RRM were positive and ranged from 0.43 to 0.80 throughout the lactation curves. The correlation between BV estimated with RTDM and RRM was 0.742 for MY and 0.664 for DMY. The RRM could be a useful alternative to RTDM for the prediction of BV in this breed.
\end{abstract}

Key words: dairy goat, test-day record, repeatability test-day model, random regression model

\section{INTRODUCTION}

Spain has the second largest goat population in the European Union and it is also the second largest producer of goat's milk (FAOSTAT, 2006). This milk is entirely destined for cheese manufacture. This fact dictates that selection objectives include traits such as milk yield and milk composition (fat, protein, and DM contents).

Received July 15, 2009.

Accepted March 4, 2010.

${ }^{1}$ Corresponding author: pa1semaj@uco.es
Many studies (Gipson and Grossman, 1990; Kominakis et al., 2000; Valencia et al., 2007) have been published on the effects of environmental factors on milk yield and composition in this specie. Díaz et al. (1999) reported estimates of these effects on milk traits in the Murciano-Granadina breed. The factors most commonly described as affecting previously mentioned traits are herd, year and month of kidding, and their first-order interactions, number of kids born, age at kidding, or the kidding number. In relation to genetic parameters, only 3 papers are available on Spanish goats: Rabasco et al. (1993) on Verata goats, and Analla et al. (1996) and Delgado et al. (2006) on Murciano-Granadina goats. In all these works, complete accumulated lactation yields were the traits under study.

Many advantages can be obtained by using the original test-day records as dependent variable in a genetic evaluation model, internationally known as test-day model, instead of accumulated values, function of the original test-day records; a comprehensive review on this subject was presented by Schaeffer (2002). Testday records can be analyzed by means of a repeatability test-day model (RTDM) as suggested by Ptak and Schaeffer (1993); however, this method gives us only a single estimate of variance components and breeding values (BV) for the whole lactation. To maximize the use of all the information available about test-day of each animal, Schaeffer and Dekkers (1994) were able to present the bases for using random regression models (RRM) to estimate breeding values and variance components for each point throughout the trajectory of the lactation curve. A short description of the differences between RTDM and RRM was presented by Schaeffer and Jamrozik (2008).

Random regression models are currently widely used for the estimation of variance components and BV prediction for traits repeatedly recorded over time (see review by Schaeffer, 2004). In the case of goats, only 3 studies using RRM have been published (Zumbach et al., 2004; Breda et al., 2006; Sarmento et al., 2006); however, in all cases the only trait studied was 
Table 1. Absolute frequencies and mean values (SD in parentheses) of monthly milk records of MurcianoGranadina goats used for the analyses

\begin{tabular}{lcc}
\hline Trait & First lactation & Second lactation \\
\hline Records (n) & 30,687 & 19,009 \\
Records/animal (n) & $5.98(2.31)$ & $6.40(2.47)$ \\
Animals (n) & 5,130 & 2,971 \\
Dams (n) & 2,082 & 1,278 \\
Sires (n) & 205 & 156 \\
Milk yield (kg/d) & $1.931(1.01)$ & $2.179(1.01)$ \\
Fat yield (g/d) & $0.098(0.05)$ & $0.109(0.05)$ \\
Protein yield (g/d) & $0.068(0.03)$ & $0.0717(0.03)$ \\
DM (g/d) & $0.263(0.13)$ & $0.295(0.136)$ \\
Fat (\%) & $5.309(1.39)$ & $5.313(1.40)$ \\
Protein (\%) & $3.565(0.54)$ & $3.588(0.54)$ \\
DM (\%) & $13.926(1.86)$ & $13.91(1.93)$ \\
DIM & $130.0(75.09)$ & $130.5(77.97)$ \\
\hline
\end{tabular}

daily milk yield, and none of the references deal with any milk composition trait. In Spain, an RRM is currently used for the evaluation of dairy cattle (Rekaya et al., 1999); however, a repeatability lactational model (RLM) applied to accumulated lactation milk yield is still used for dairy goats and sheep (Serradilla, 2008). Nevertheless, this simpler model assumes that records taken at different lactations are expressions of the same trait.

The fact that monthly milk yield and composition records from Murciano-Granadina goats are available will allow us to use either RTDM or RRM as a good alternative to the official RLM presently used in this breed. From a practical point of view, breeders are more familiar with accepting EBV based on a single cumulative value obtained with all the records of each lactation, but this can be also achieved with greater precision using RTDM by simply multiplying the estimated genetic effects by the number of days of lactation (Ptak and Schaeffer, 1993).

Therefore, the objective of this paper is to use the RRM to estimate variance components and $\mathrm{BV}$ for the first and second lactations using test-day records of milk production, protein, fat, and DM yields. In addition, we aim to compare the genetic parameters and BV estimations obtained with RRM with those obtained with RTDM, which assume the same (co)variance throughout the lactations.

\section{MATERIALS AND METHODS}

The milk recording system of the Murciano-Granadina goat is based on International Committee for Animal Recording (ICAR,; Rome, Italy) rules. A monthly visit is made to each herd by official technicians and the milk yield in a single milking of each animal is recorded. A sample of milk from each milking is sent to the laboratory to analyze milk composition. A total of 71,454 monthly records of milk (MY), protein (PY), fat $(\mathbf{F Y})$, and DM (DMY) yields, collected between January 2000 and August 2006, were supplied for this study by the National Breeders Association of Murciano-Granadina Goats (Albolote, Granada, Spain). The raw data were thoroughly edited and validated. Records collected during the first $7 \mathrm{~d}$ after kidding and those recorded after $320 \mathrm{~d}$, those corresponding to parturitions with more than 5 kids, and those considered as outliers $(\mu \pm 3 \mathrm{SD})$ were discarded. The remaining 63,640 records (first to fifth lactations) were grouped in consecutive weeks up to a maximum of 40 wk per lactation, but only 49,696 records from the first 2 lactations were used (Table 1) because the other lactations were poorly represented in the database both in terms of production records and genealogical information. These records belong to 5,163 goats, offspring of 206 bucks and 2,086 does $(1,554$ of which are represented in the data vector with 18,465 records, of which 52.4 and $47.6 \%$ correspond to first and second lactations, respectively). These animals were distributed in 20 herds that were connected through both AI sires (11 bucks with 227 daughters having 1,927 records) and the dam paths. The pedigree records included 6,037 animals.

The dependent variables (MY, FY, PY, and DMY) recorded in the first and second lactation were analyzed with 3 models. The first 2 models were RRM. The first RRM (model A) used a first-order Legendre polynomial for random regression and the second RRM (model B) used a second-order Legendre polynomial. These models analyzed the records of each lactation as a different but correlated trait. The third model was an RTDM. This model assumed that first and second lactations are the same trait. Both variance components and BV for all 3 models were estimated using ASREML software (Gilmour et al., 2000). The RRM was defined as 


$$
\begin{aligned}
& y_{i j k l m n}=H T D_{i}+L S_{j}+\left[\sum_{r=0}^{3} \Phi_{r} \beta_{1 r}\right]_{k}+\left[\sum_{r=0}^{2} \Phi_{r} \beta_{2 r}\right]_{l} \\
& +\left[\sum_{r=0}^{2} \Phi_{r} a_{r}\right]_{m}+\left[\sum_{r=0}^{2} \Phi_{r} p_{r}\right]_{n}+e_{i j k l m n},
\end{aligned}
$$

where $y_{i j k l m n}$ is the dependent variable recorded in the $i$ th level of $H T D_{i}$ (herd-date of recording with $240 \mathrm{lev}-$ els), the $j$ th level of $L S_{j}$ (litter size with 3 levels) in the $k$ th lactation $(k=1,2)$ and the $l$ th number of milkings per day $(l=1,2) ; \beta_{1 r}$ and $\beta_{2 r}$ are fixed Legendre polynomial regressions coefficients for weeks in lactation within $k$ th lactation and $l$ th number of milkings $\left(N M_{l}\right)$ per day, respectively; $a_{r}$ is the additive genetic effect associated with the $r$ th Legendre coefficient for the $m$ th animal in the pedigree $(m=6,037$ animals $) ; p_{r}$ is the permanent environmental effect associated with the $r$ th Legendre coefficient for the $n$th animal with record $(n$ $=5,163$ animals); and $e$ is a vector of random residuals. The terms $\Phi_{r}$ contain the $r$ th coefficients of the Legendre polynomial at the lactation week in which the record was taken, being this time expressed in standardized form (between -1 and +1 ). For the presented model the variance-covariance $(\mathbf{V})$ matrix between records was assumed to be

$$
\mathbf{V}=\mathbf{Z}_{1} \mathbf{G Z}_{1}^{\prime}+\mathbf{Z}_{2} \mathbf{P Z}_{2}^{\prime}+\mathbf{R}
$$

where $\mathbf{Z}_{1}$ to $\mathbf{Z}_{2}$ are the incidence matrices connecting the random effects with the dependent variables and containing the $\Phi_{r}$ elements, and

$$
\begin{aligned}
& \mathbf{G}=\mathbf{G}_{\mathbf{0}} \otimes \mathbf{A} \\
& \mathbf{P}=\mathbf{P}_{\mathbf{0}} \otimes \mathbf{I}_{\mathbf{n}} \\
& \mathbf{R}=\mathbf{R}_{\mathbf{0}} \otimes \mathbf{I}_{\mathbf{e}},
\end{aligned}
$$

where $\mathbf{A}$ is the numerator relationship matrix between animals and $\mathbf{I}_{\mathrm{n}}$ and $\mathbf{I}_{\mathrm{e}}$ are diagonal matrices, with

$$
\begin{gathered}
\mathbf{G}_{0}=\left[\begin{array}{cc}
\mathbf{K}_{\mathrm{a} 1} & \mathbf{K}_{\mathrm{a}_{2,1}} \\
\mathbf{K}_{\mathrm{a}_{1,2}} & \mathbf{K}_{\mathrm{a} 2}
\end{array}\right] \\
\text { and } \\
\mathbf{P}_{\mathbf{0}}=\left[\begin{array}{cc}
\mathbf{K}_{\mathrm{n} 1} & 0 \\
0 & \mathbf{K}_{\mathrm{n} 2}
\end{array}\right] .
\end{gathered}
$$

In $\mathbf{G}_{\mathbf{0}}$, the expressions $\mathbf{K}_{\mathrm{a} 1}, \mathbf{K}_{\mathrm{a} 2}, \mathbf{K}_{\mathrm{a} 2, \mathbf{1}}$, and $\mathbf{K}_{\mathrm{a} 1,2}$ are the genetic (co)variance matrices of the same order (3 $\times 3$ ) of random regression coefficients of the first and second lactations, respectively, whereas $\mathbf{K}_{\mathrm{n} 1}$ and $\mathbf{K}_{\mathrm{n} 2}$ are permanent environmental (co)variance matrices of the same order $(3 \times 3)$ between random regression coefficients for first and second lactation, respectively (note that these effects are assumed to be uncorrelated across lactation). The matrix $\mathbf{R}_{0}$ is a $2 \times 2$ diagonal matrix of random residual variance for first and second lactations. The Legendre polynomials $\Phi_{1}$ and $\Phi_{2}$ for the first and second lactations, respectively, have the same numbers of elements ( $r$ order) and the same numbers of weeks of lactation. Following Jamrozik and Schaeffer (1997), handling the appropriate elements for $\mathbf{G}_{\mathbf{0}}, \mathbf{P}_{\mathbf{0}}$, and the corresponding elements in $\mathbf{R}_{0}$ we can estimate the heritability and the genetic correlations $\left(\mathbf{r}_{\mathrm{g}}\right)$ within and across lactations for each trait and each week of lactation.

Two RRM models with 2 different fitting orders for random effects $(\mathrm{r}=1$ for model $\mathrm{A}$ and $\mathrm{r}=2$ for model B) were compared and tested. Both models included the same fixed effects described above. Following the recommendations of Foulley and Robert-Granié (2002), $\log \mathrm{L}$, Akaike information criteria, and Bayesian information criteria were used to select the model that best fitted the data:

$$
\begin{gathered}
\mathrm{AIC}=-2 \log £+2 \mathrm{p} \text { and } \\
\mathrm{BIC}=-2 \log £+\mathrm{p} \times \log (\mathrm{N}-\mathrm{x}),
\end{gathered}
$$

where $\log £$ is the $\log$ of the maximum likelihood of the model, $\mathrm{p}$ is the number of components of the estimated (co)variance, and $\mathrm{N}-\mathrm{x}$ represents the residual degrees of freedom.

The solution for each animal contains $\mathbf{a}_{\mathrm{i}}$ genetic random regression coefficients for $k$ lactation, which were used to estimate the $\mathrm{BV}\left(\mathbf{B V}_{\mathrm{i}}\right)$ for any $w$ points of the first and second lactation by means of

$$
\mathbf{B V}_{\mathrm{w}}^{\mathrm{i}}=\Phi_{\mathrm{w}} \mathbf{a}_{\mathrm{ik}}^{\prime},
$$

where $\mathbf{a}_{\mathbf{i k}}$ represents the solution for animal $i$ and $k$ lactation $\left(\mathbf{a}_{\mathbf{0}}\right.$ for the intercept, $\mathbf{a}_{1}$ for the linear regression coefficient, and $\mathbf{a}_{2}$ for the quadratic regression coefficient) given for the second-order Legendre polynomial for each lactation.

In addition, following the proposal of Jamrozik et al. (1997), the $\mathrm{BV}$ for persistence $\left(\mathrm{BV}_{\mathrm{PER}}\right)$ of milk yield between 2 points, $w_{1}$ and $w_{2}$, of the lactation curve can be estimated as the area of a triangle of which the height is the difference between the BV of the animals at these points of lactation, $\mathbf{B V}_{\mathbf{w} 1}$ and $\mathbf{B V}_{\mathbf{w} 2}$. For example, the breeding value for persistence of a given 
Table 2. Order of fit ${ }^{1}$ and values of the information criteria $\left(\log \mathrm{L}, \mathrm{AIC}\right.$, and $\left.\mathrm{BIC}^{2}\right)$ computed to compare the polynomials used in both models tested for the analysis of daily milk and DM yields in Murciano-Granadina goats

\begin{tabular}{lccccrc}
\hline Item $^{3}$ & Animal & Residual & Parameters (n) & $\log \mathrm{L}$ & AIC & BIC \\
\hline Daily milk yield & 1 & 2 & 18 & 24,781 & $-49,526$ & $-49,367$ \\
$\quad$ Model A & 2 & 2 & 35 & 25,280 & $-50,490$ & $-50,182$ \\
Model B & 1 & 2 & 18 & $-4,646.9$ & 9,329 & 9,488 \\
Daily DM yield & 2 & 2 & 35 & $-4,160.0$ & 8,390 & 8,698 \\
Model A & & & & & \\
Model B &
\end{tabular}

${ }^{1}$ The order of fit was the same for first and second lactations. The order of fit for the individual environmental permanent effect was the same as for the animal effect.

${ }^{2} \mathrm{AIC}=$ Akaike information criteria; $\mathrm{BIC}=$ Bayesian information criteria.

${ }^{3}$ Model A = random regression model using a first-order Legendre polynomial for random regression; model B = random regression model using a second-order Legendre polynomial for random regression. The difference between models A and B is the order of fit for genetic and individual permanent effects. The greater the $\log \mathrm{L}$ and the smaller the AIC and the BIC, the better the model fits.

animal between the 17 th week $(120 \mathrm{~d})$ and the 35 th week $(240 \mathrm{~d})$ of lactation is

$$
\mathrm{BV}_{\mathrm{PER}}=\frac{1}{2}\left(\mathrm{BV}_{35}-\mathrm{BV}_{17}\right) \times 120 .
$$

Finally, the same data set (all monthly records from the first and second lactations) was used to estimate the genetic variance and the BV of the animals, assuming the dependent variables to be the same trait along the trajectory of lactations, with the following RTDM model:

$$
\begin{aligned}
& y_{i j k l m n}=H T D_{i}+L S_{j}+L N_{k} \\
& +\sum_{r=0}^{2} \beta_{1 r} Z_{1}\left(N M_{l}\right)+a_{m}+p_{n}+e_{i j k l m n} .
\end{aligned}
$$

This model assumes that variances of random effects in the model are constant throughout both lactation periods, which implies a constant BV for the whole lactation and no variability in the lactation curve shape across animals.

The standard errors of genetic parameters are estimated with ASREML software as a linear function of the errors of the corresponding variance components. At the same time, the predicted error variances (PEV) for the BV were used to calculate the accuracy of the genetic evaluations (ACC) as the correlation between true and the predicted $\mathrm{BV}$ :

$$
\mathrm{ACC}_{i}=\sqrt{\left(1-\mathrm{PEV}_{i} / \mathrm{Var}_{i}\right.},
$$

where $\operatorname{Var}_{i}$ is the genetic variance of the trait. The standard errors of genetic parameters and the accuracy of the genetic evaluations of $\mathrm{BV}$ were computed at the middle point of the lactation curve (approximately 20 wk).

\section{RESULTS}

Absolute frequencies and mean values and their standard deviations of monthly milk records for MurcianoGranadina goats used for the analyses are presented in Table 1 . The number of records per animal was more or less the same in both lactations $(>1,000$ observations wk) up to wk 35, when it started to decline until the end of the milking period. The yields in the first lactation were always lower than in the second, but the shape of the lactation curve was very similar for both lactations (results not shown). Also, the fixed effects included in the model were highly significant for all the dependent variables (results not shown).

Table 2 shows the values of the statistical criteria used for the comparison between the RRM models for the analysis of daily MY and DMY. For both traits all
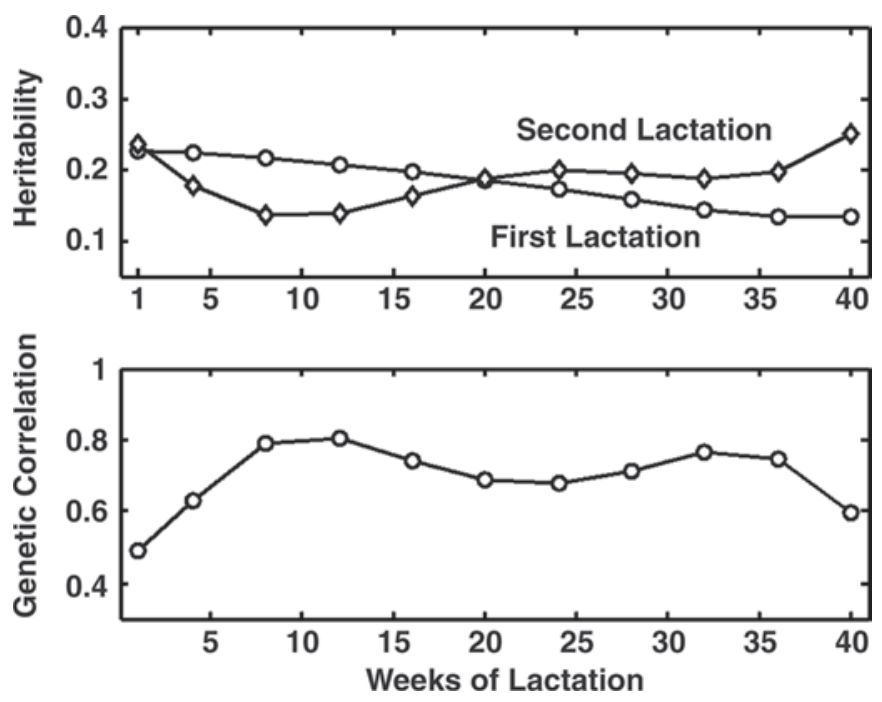

Figure 1. Change through lactation of the heritability and the genetic correlation between records for the first $(\bigcirc)$ and second $(\diamond)$ lactations, estimated with a random regression model for milk yield in Murciano-Granadina goats. 

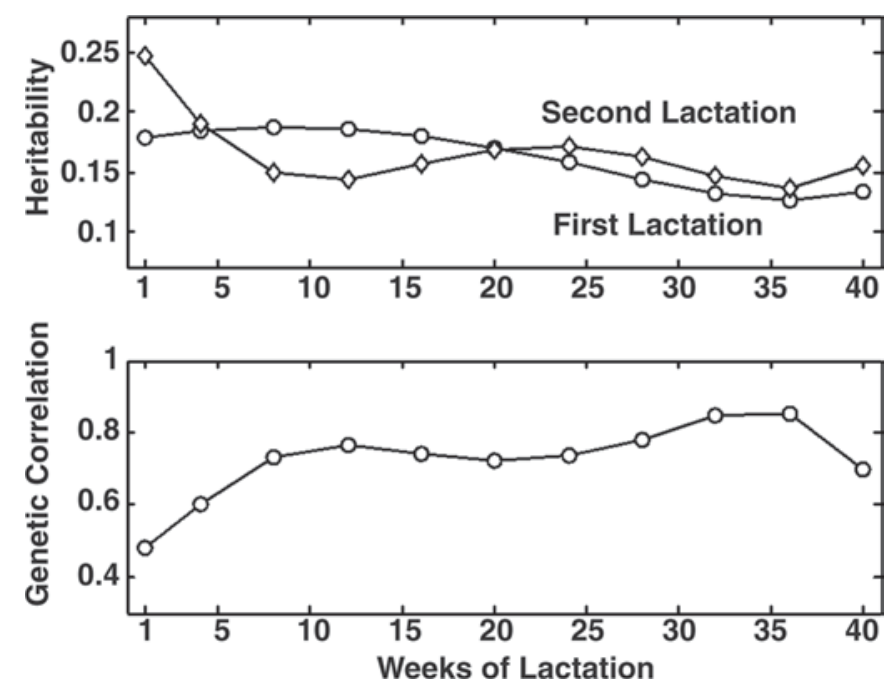

Figure 2. Change through lactation of the heritability and the genetic correlation between records for the first $(\bigcirc)$ and second $(\diamond)$ lactations, estimated with a random regression model for fat yield in Murciano-Granadina goats.

the statistical criteria pointed to model $\mathrm{B}$ as the best for fitting this data set.

Figures 1, 2, 3, and 4 show the change over the 40wk lactation period of the heritability and the genetic correlations between the first and second lactations for each trait studied. Estimates of heritability for MY and FY were very similar for both lactations. The $r_{\mathrm{g}}$ between both lactations ranged from 0.45 to 0.80 for both traits throughout the lactation period. The heritability of PY was stable during the first lactation (between 0.16 and 0.17 ) and fluctuated (between 0.10 and 0.18 ) in the
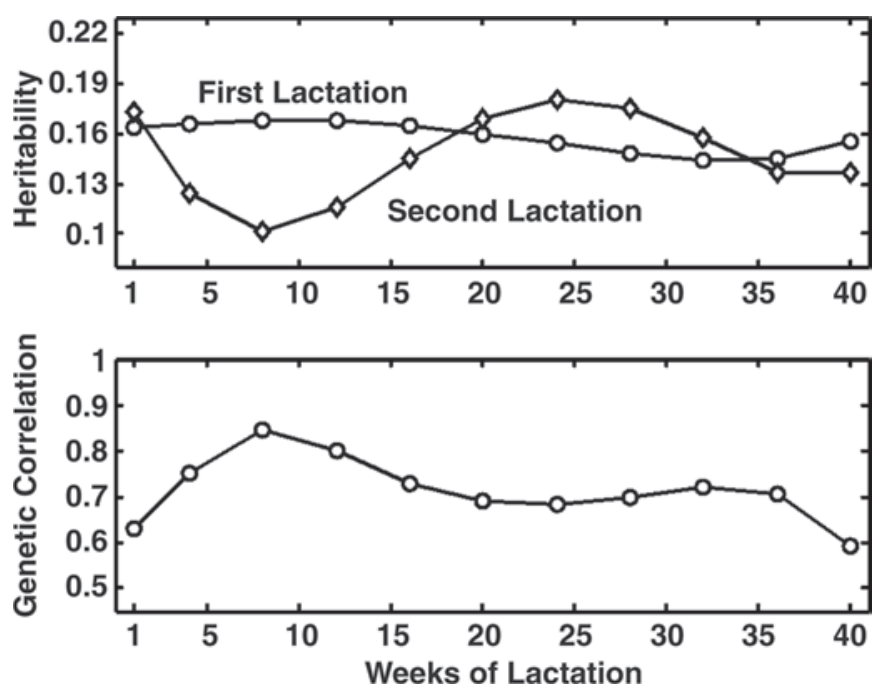

Figure 3. Change through lactation of the heritability and the genetic correlation between records for the first $(\bigcirc)$ and second $(\diamond)$ lactations, estimated with a random regression model for protein yield in Murciano-Granadina goats. second lactation. The value of $\mathrm{r}_{\mathrm{g}}$ ranged from 0.60 to 0.85 for PY in both lactations. The value of heritability for DMY varied from 0.24 to 0.15 for the first lactation and from 0.25 to 0.12 for the second lactation, and $r_{g}$ for this trait varied from 0.43 to 0.79 .

Estimates of repeatability for selected points (weeks of lactation) and of $r_{g}$ between pairs of points, through the lactation curve, are shown for each lactation in Tables 3, 4, 5, and 6 for MY, FY, PY, and DMY, respectively. In general terms, the $r_{g}$ patterns were very similar, showing positive values throughout the lactation period. Genetic correlations between weeks in lactation in the first lactation are higher and more stable than in the second lactation for all traits. The estimates of $r_{\mathrm{g}}$ for records up to 4 wk apart were greater than 0.90 , whereas those for records between 8 and 16 wk apart ranged from 0.70 to 0.85 .

Repeatability decreased during the first lactation period for all traits with the exception of PY, and showed slighter higher values at the extreme points of the lactation (bottom lines in Tables 3 to 6) for the second lactation. In the middle of the lactation period, the repeatability values were more stable for all traits in both lactations.

The genetic parameters estimated with RRM and RTDM at wk 20 of lactation are presented in Table 7 . Heritability and repeatability estimates obtained with RTDM were higher for MY, DMY, and FY than those obtained with RRM. The opposite occurred with the estimates of PY. The standard errors of the heritability and repeatability estimates were very similar in both models. Table 8 shows the range of the BV estimated with RTDM and RRM for 2 representative traits, MY and DMY. As indicated by the range of the EBV, an important amount of genetic variability exists for both traits within this breed. The accuracy of BV predicted for MY with RRM was higher than that of BV predicted with RTDM, the gain in accuracy being greater for DMY than for MY. Correlations between BV predicted with RRM and RTDM were 0.742 and 0.664 for MY and DMY, respectively. This indicates that a certain reranking of animals can be expected when shifting from one model to the other. Only approximately $50 \%$ of the best 500 animals selected by their EBV in each model coincided across models.

\section{DISCUSSION}

The use of random regression models for genetic evaluation has become a standard procedure in many animal breeding scenarios (see review of Schaeffer, 2004). They have also been successfully applied to the genetic evaluation of goats (Breda et al., 2006; Zumbach et al., 2008). Our results confirm the advantage of using RRM 

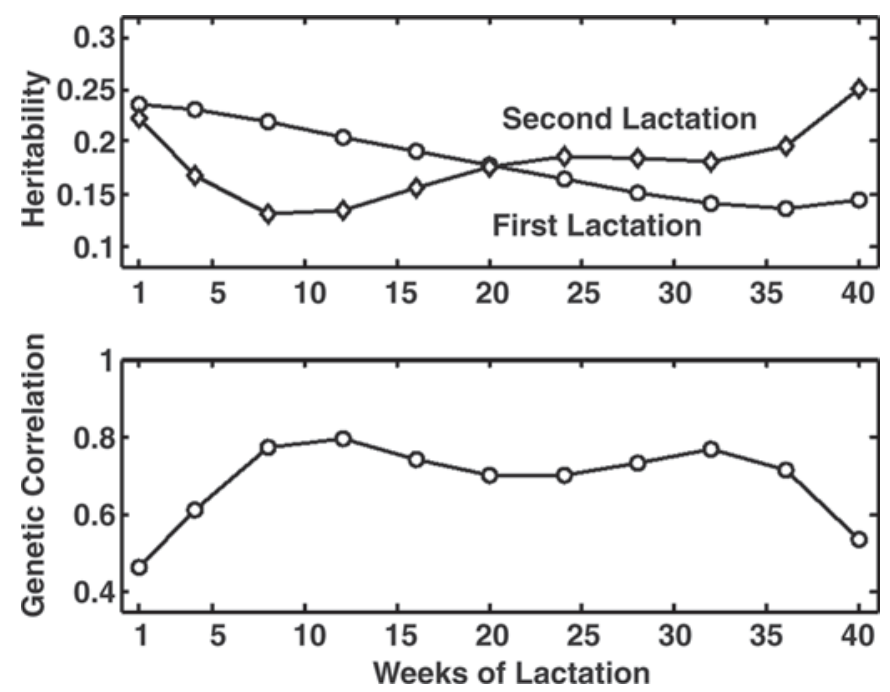

Figure 4. Change through lactation of the heritability and the genetic correlation between records for the first $(\bigcirc)$ and second $(\diamond)$ lactations, estimated with a random regression model for DM yield in Murciano-Granadina goats.

over other methods such as RTDM, which, although having the advantage of using the original test-day records instead of cumulative value per lactation, assumes the same covariance structure across lactations.

The genetic correlations between pairs of records taken throughout the lactation period (Tables 3 to 6 ) are positive and generally high for the 4 traits studied, particularly for records up to 4 wk apart. Similar results were obtained with goat records by Zumbach et al. (2004), Breda et al. (2006), and Sarmento et al. (2006). This has also been the general pattern observed in dairy cattle (Lopez Romero and Carabaño, 2003) and dairy sheep (Serrano et al., 2001). As in all previously cited works, in the present study, the greater the interval between records, the smaller the value of $r_{\mathrm{g}}$.
Nevertheless, it is evident that any selection process based on monthly records will produce positive effects at all points of the lactation curve.

The estimates of heritability and $r_{g}$ obtained in this work are within the range of results reported previously for the same breed (Analla et al., 1996; Delgado et al., 2006) when applying multivariate lineal models to total MY and average protein and fat contents previously standardized to $240 \mathrm{~d}$ of lactation. The only 2 works applying RRM to dairy goat records (Breda et al., 2006; Zumbach et al., 2008) reported results for MY very similar to those of Figure 2. The latest results and those that we have obtained with RTDM were within the range of values internationally reported for this species (Ilahi et al., 2000; Muller et al., 2002; Olivier et al., 2005; Sarmento et al., 2006). All traits show some fluctuations in the pattern of heritability along the lactation trajectory, which could be related to some artifact associated with the use of Legendre polynomial. Nevertheless, it is important to point out that our results with RRM constitute the first report available in which the genetic parameters are shown for milk composition traits throughout the trajectory of the first and second lactation periods in goats.

Our results also show that genetic variances of all traits studied are inconstant through lactation and that the genetic correlations between the first and second lactation records of milk traits are not close to 1 (Figures 1, 2, 3, and 4). Therefore, the assumption made in RTDM, that all the records from both lactations are the expression of the same trait, is not supported by the results of our study. The same conclusion was reached by Zumbach et al. (2008) in a similar analysis carried out with dairy goats in Germany. According to these results, it was not surprising that there was a low correlation between the estimates of BV obtained with both

Table 3. Genetic correlations ${ }^{1}$ between milk yields recorded at different weeks in lactation for first (above diagonal line) and second (below diagonal line) lactation in Murciano-Granadina goats ${ }^{2}$

\begin{tabular}{|c|c|c|c|c|c|c|c|c|c|c|c|}
\hline $\begin{array}{l}\text { Week of } \\
\text { lactation }\end{array}$ & 1 & 4 & 8 & 12 & 16 & 20 & 24 & 28 & 32 & 36 & 40 \\
\hline 1 & & 0.987 & 0.931 & 0.845 & 0.753 & 0.677 & 0.627 & 0.606 & 0.610 & 0.618 & 0.501 \\
\hline 4 & 0.970 & & 0.977 & 0.919 & 0.847 & 0.783 & 0.737 & 0.711 & 0.698 & 0.669 & 0.592 \\
\hline 12 & 0.454 & 0.657 & 0.913 & & 0.988 & 0.963 & 0.935 & 0.905 & 0.855 & 0.749 & 0.560 \\
\hline 16 & 0.189 & 0.420 & 0.760 & 0.959 & & 0.993 & 0.976 & 0.949 & 0.894 & 0.768 & 0.549 \\
\hline 20 & 0.038 & 0.274 & 0.646 & 0.898 & 0.985 & & 0.995 & 0.975 & 0.922 & 0.792 & 0.560 \\
\hline 24 & -0.02 & 0.208 & 0.582 & 0.851 & 0.958 & 0.992 & & 0.992 & 0.950 & 0.830 & 0.603 \\
\hline 36 & 0.291 & 0.388 & 0.517 & 0.579 & 0.595 & 0.623 & 0.686 & 0.793 & 0.927 & & 0.942 \\
\hline 40 & 0.465 & 0.467 & 0.425 & 0.337 & 0.279 & 0.283 & 0.349 & 0.480 & 0.702 & 0.918 & \\
\hline $\mathrm{REP}_{1}$ & 0.327 & 0.333 & 0.338 & 0.339 & 0.335 & 0.329 & 0.320 & 0.310 & 0.298 & 0.286 & 0.279 \\
\hline $\mathrm{REP}_{2}$ & 0.425 & 0.378 & 0.335 & 0.320 & 0.323 & 0.330 & 0.333 & 0.331 & 0.332 & 0.351 & 0.401 \\
\hline
\end{tabular}

\footnotetext{
${ }^{1}$ All parameters were estimates with a second-order 2 traits random regression model.

${ }^{2}$ Repeatability values for the first and second lactations $\left(\mathrm{REP}_{1}\right.$ and $\mathrm{REP}_{2}$, respectively) are presented in the last 2 lines.
} 
Table 4. Genetic correlations ${ }^{1}$ between fat yields recorded at different weeks in lactation for first (above diagonal line) and second (below diagonal line) lactation in Murciano-Granadina goats ${ }^{2}$

\begin{tabular}{lccccccccccc}
\hline $\begin{array}{l}\text { Week of } \\
\text { lactation }\end{array}$ & 1 & 4 & 8 & 12 & 16 & 20 & 24 & 28 & 32 & 36 & 40 \\
\hline 1 & & 0.984 & 0.921 & 0.837 & 0.755 & 0.688 & 0.640 & 0.609 & 0.585 & 0.547 & 0.473 \\
4 & 0.972 & & 0.976 & 0.921 & 0.858 & 0.803 & 0.759 & 0.722 & 0.679 & 0.605 & 0.481 \\
8 & 0.813 & 0.926 & & 0.984 & 0.949 & 0.911 & 0.874 & 0.833 & 0.772 & 0.660 & 0.481 \\
12 & 0.550 & 0.729 & 0.933 & & 0.990 & 0.969 & 0.941 & 0.903 & 0.833 & 0.697 & 0.482 \\
16 & 0.320 & 0.531 & 0.811 & 0.966 & & 0.994 & 0.977 & 0.944 & 0.873 & 0.729 & 0.469 \\
20 & 0.178 & 0.399 & 0.712 & 0.915 & 0.987 & & 0.994 & 0.970 & 0.908 & 0.767 & 0.532 \\
24 & 0.115 & 0.336 & 0.657 & 0.877 & 0.967 & 0.994 & & 0.990 & 0.944 & 0.820 & 0.596 \\
28 & 0.124 & 0.335 & 0.643 & 0.854 & 0.944 & 0.976 & 0.992 & & 0.980 & 0.888 & 0.694 \\
32 & 0.212 & 0.396 & 0.657 & 0.826 & 0.893 & 0.921 & 0.946 & 0.978 & & 0.962 & 0.822 \\
36 & 0.376 & 0.503 & 0.661 & 0.736 & 0.750 & 0.759 & 0.791 & 0.856 & 0.944 & \\
40 & 0.548 & 0.586 & 0.590 & 0.532 & 0.472 & 0.452 & 0.484 & 0.576 & 0.732 & 0.915 \\
$\mathrm{REP}_{1}$ & 0.310 & 0.318 & 0.332 & 0.343 & 0.347 & 0.345 & 0.337 & 0.324 & 0.308 & 0.293 & 0.289 \\
$\mathrm{REP}_{2}$ & 0.396 & 0.343 & 0.294 & 0.274 & 0.275 & 0.282 & 0.290 & 0.297 & 0.307 & 0.327 & 0.364 \\
\hline
\end{tabular}

${ }^{1}$ All parameters were estimates with a second-order 2 traits random regression model.

${ }^{2}$ Repeatability values for the first and second lactations $\left(\mathrm{REP}_{1}\right.$ and $\mathrm{REP}_{2}$, respectively) are presented in the last 2 lines.

Table 5. Genetic correlations ${ }^{1}$ between protein yields recorded at different weeks in lactation for first (above diagonal line) and second lactation (below diagonal line) in Murciano-Granadina goats ${ }^{2}$

\begin{tabular}{|c|c|c|c|c|c|c|c|c|c|c|c|}
\hline $\begin{array}{l}\text { Week of } \\
\text { lactation }\end{array}$ & 1 & 4 & 8 & 12 & 16 & 20 & 24 & 28 & 32 & 36 & 40 \\
\hline 1 & & 0.985 & 0.927 & 0.849 & 0.775 & 0.717 & 0.678 & 0.655 & 0.641 & 0.619 & 0.571 \\
\hline 4 & 0.958 & & 0.978 & 0.927 & 0.871 & 0.823 & 0.786 & 0.758 & 0.727 & 0.676 & 0.587 \\
\hline 12 & 0.378 & 0.628 & 0.919 & & 0.991 & 0.972 & 0.949 & 0.918 & 0.863 & 0.762 & 0.600 \\
\hline 16 & 0.148 & 0.425 & 0.797 & 0.971 & & 0.995 & 0.980 & 0.953 & 0.897 & 0.788 & 0.613 \\
\hline 20 & 0.029 & 0.312 & 0.717 & 0.933 & 0.992 & & 0.995 & 0.975 & 0.926 & 0.820 & 0.644 \\
\hline 32 & 0.116 & 0.371 & 0.725 & 0.902 & 0.945 & 0.956 & 0.967 & 0.986 & & 0.973 & 0.873 \\
\hline 36 & 0.310 & 0.517 & 0.767 & 0.852 & 0.849 & 0.843 & 0.857 & 0.898 & 0.959 & & 0.963 \\
\hline 40 & 0.559 & 0.669 & 0.734 & 0.672 & 0.598 & 0.566 & 0.582 & 0.646 & 0.763 & 0.916 & \\
\hline $\mathrm{REP}_{1}$ & 0.294 & 0.333 & 0.308 & 0.308 & 0.308 & 0.308 & 0.308 & 0.309 & 0.333 & 0.333 & 0.308 \\
\hline $\mathrm{REP}_{2}$ & 0.412 & 0.333 & 0.307 & 0.307 & 0.307 & 0.307 & 0.308 & 0.308 & 0.333 & 0.333 & 0.308 \\
\hline
\end{tabular}

${ }^{1}$ All parameters were estimates with a second-order 2 traits random regression model.

${ }^{2}$ Repeatability values for the first and second lactations $\left(\mathrm{REP}_{1}\right.$ and $\mathrm{REP}_{2}$, respectively) are presented in the last 2 lines.

Table 6. Genetic correlations ${ }^{1}$ between DM yields at different weeks in lactation for first (above diagonal line) and second (below diagonal line) lactation in Murciano-Granadina goats ${ }^{2}$

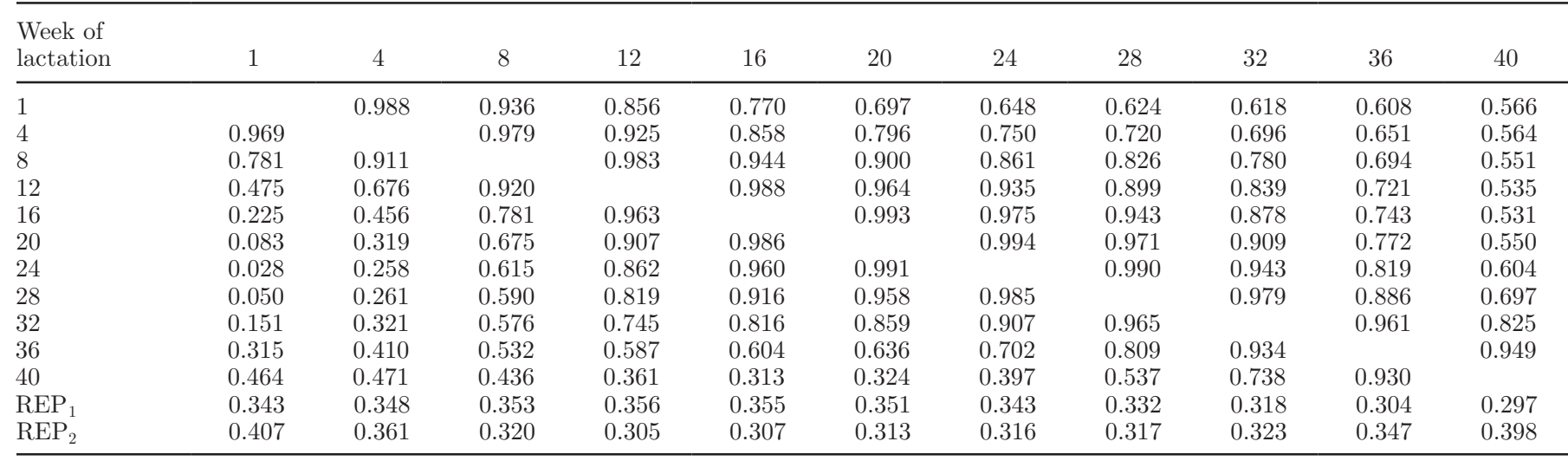

${ }^{1}$ All parameters were estimates with a second-order 2 traits random regression model.

${ }^{2}$ Repeatability values for the first and second lactations $\left(\mathrm{REP}_{1}\right.$ and $\mathrm{REP}_{2}$, respectively) are presented in the last 2 lines. 
Table 7. Genetic parameters ${ }^{1}$ and standard errors for dairy traits in Murciano-Granadina goats, estimated with a random regression model and with a repeatability test-day model

\begin{tabular}{lccccc}
\hline & \multicolumn{2}{c}{ Random regression model $^{2}$} & & \multicolumn{2}{c}{ Repeatability test-day model } \\
\cline { 2 - 3 } \cline { 5 - 6 } Trait & Heritability & Repeatability & & Heritability & Repeatability \\
\hline Milk yield & $0.191 \pm 0.02$ & $0.329 \pm 0.01$ & & $0.215 \pm 0.02$ & $0.405 \pm 0.01$ \\
Fat yield & $0.172 \pm 0.01$ & $0.345 \pm 0.02$ & & $0.178 \pm 0.01$ & \\
Protein yield & $0.160 \pm 0.01$ & $0.308 \pm 0.01$ & & $0.137 \pm 0.01$ & \\
DM yield & $0.170 \pm 0.02$ & $0.351 \pm 0.01$ & & $0.202 \pm 0.02$ & $0.395 \pm 0.01$ \\
\hline
\end{tabular}

${ }^{1}$ All parameters are expressed at the middle of lactation period (at approximately $20 \mathrm{wk}$ ).

${ }^{2}$ Estimations correspond to first lactation; they were very similar for second lactation (Figures 1, 2, 3, and 4).

models when the same data set was analyzed (Table 8). More appropriate modeling of the data through the lactation trajectory can be made with RRM than with RTDM, thus generating more accurate BV predictions. This represents a nonnegligible advantage for the selection program of the breed.

Because of the structure of the data set available, it was not possible to test a greater degree of fit. Nevertheless, the experience with RRM using third to fifthorder polynomials (Lopez Romero and Carabaño, 2003 and Druet et al., 2005 for dairy cattle; Kominakis et al., 2001 for dairy sheep; Breda et al., 2006 for dairy goats) shows that most of the genetic variability can be explained by the first 2 eigenvalues of the additive genetic regression coefficients. In that sense, a principal components analysis was applied to our general results for $\mathbf{G}_{\mathbf{0}}(6 \times 6$ genetic regression coefficients matrix $)$, showing that from 91 to $95.3 \%$ of the genetic variability was explained by the first 3 eigenvalues. When the same analysis was independently repeated for each lactation $\left(\mathrm{K}_{\mathrm{a} 1}\right.$ and $\left.\mathrm{K}_{\mathrm{a} 2}\right)$, it was found that between 80.3 and $92.5 \%$ of the genetic variability for the first and second lactations, respectively, could be explained by the first 2 eigenvalues. These results show the same general pattern as that reported by the authors previously cited.
Our results showed that the second eigenvector (the one related to the shape of the lactation curve) explains an important part of the genetic variability in both lactations. Therefore, it would be feasible to modify the shape of the curve by selective breeding (Kirkpatrick et al., 1990, 1994). As an example, let us consider that in this goat population the estimate of the heritability for persistence in milk yield between wk 17 and 35 in lactation was 0.208 , the EBV for this persistency ranging from -28.9 to $36.3 \mathrm{~kg}$. Persistency of lactation in dairy cattle has been proven to have an important genetic determination (see review by Cobucci et al., 2003), whereas in small ruminants, the evidence is scarce. More research on this subject is needed.

\section{CONCLUSIONS}

Our study showed that genetic variances are not constant during first and second lactations and that a correlation lower than 1 exists between different points in the lactation curve. This pattern varies from first to second lactation, and correlations $<1$ between the same week in first and second lactations were observed. Thus, the hypothesis under RLM and RTDM (all records within each lactation assumed to be expression of the same trait) does not hold in our population. First

Table 8. Range and accuracy of breeding values ${ }^{1}$ (BV) for milk yield and DM yield estimated by a repeatability test-day model (RTDM) and a random regression model (RRM), and correlations between BV obtained with both models

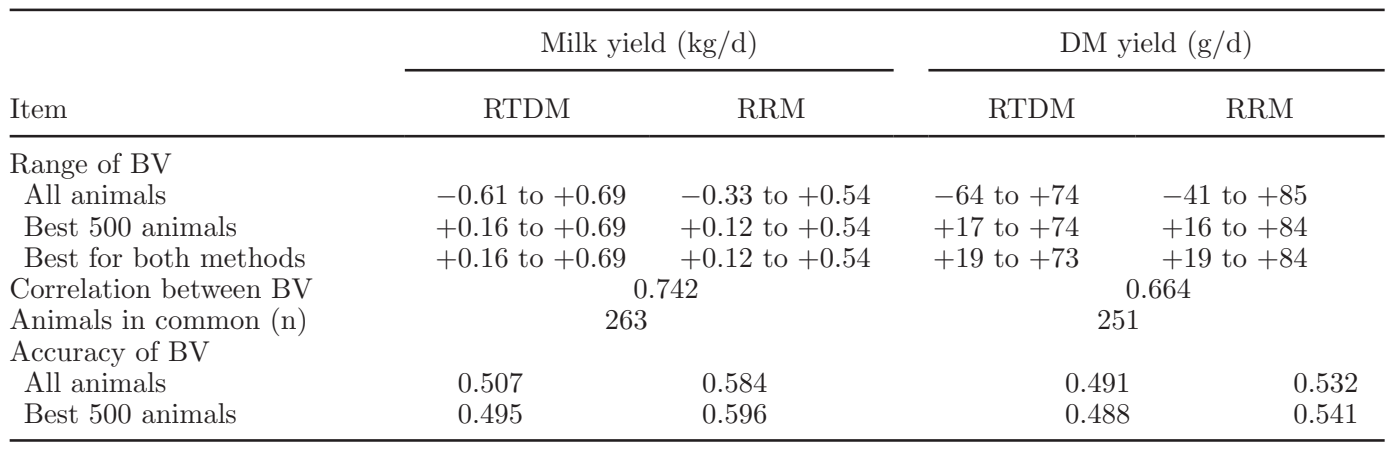

${ }^{1}$ Breeding values are expressed at the middle of lactation period (at approximately $20 \mathrm{wk}$ ). 
and second lactation measurements could be considered also as 2 different but correlated traits. Therefore, BV estimates from RRM will be more accurate than the ones presently obtained with RLM and, therefore, they would be preferable for selection purposes in this breed because they are expected to generate a higher genetic response. In addition, evaluations based on RRM models may allow for selection on the shape of the lactation curve.

\section{ACKNOWLEDGMENTS}

This work was financed by INIA funds through the project RTA-03 085 (Spanish National Program of Resources and Agro-Alimentary Technologies). We express our gratitude to the Goat Milk Recording Nucleus of COVAP Cooperative (Capricovap; Pozoblanco, Córdoba, Spain) and to the National Murciano-Granadina Breed Association (Albolote, Granada, Spain) for the provision of production and genealogical records. The authors of this paper express their gratitude to the reviewers for their useful suggestions.

\section{REFERENCES}

Analla, M., I. Jiménez-Gamero, A. Muñoz-Serrano, J. M. Serradilla, and A. Falagan. 1996. Estimation of genetic parameters for milk yield and fat and protein contents of milk from MurcianaGranadina goats. J. Dairy Sci. 79:1895-1898.

Breda, F. C., L. G. Albuquerque, M. Yamaki, J. C. R. Filho, J. L. R. Sarmento, P. S. Lopes, and M. T. Rodriguez. 2006. Genetic parameters for test day milk yield of Alpine goats. Rev. Brasil. Zootec. 35:396-404.

Cobucci, J. A., R. F. Euclydes, C. S. Pereira, R. de Almeida Torres, C. N. Costa, and P. S. Lopes. 2003. Persistency in lactation-A review. Arch. Latin. Prod. Anim. 11:163-173.

Delgado, J. V., J. M. León, L. T. Gama, J. Lozano, J. Quiroz, and M. E. Camacho. 2006. Genetic parameters for milk yield traits in Murciano Granadina goats in the high lands. In Proc. 8th World Congress on Genetics Applied to Livestock Production, August 13-18, Belo Horizonte, MG, Brazil. Communication 02-13. CD ROM. Federal University of Minas Gerais, Belo Horizonte, Brazil.

Díaz, E., M. Analla, A. Muñoz-Serrano, A. Alonso-Moraga, and J. M. Serradilla. 1999. Variation of milk yield and contents of total casein and casein fractions in Murciano-Granadina goats. Small Rumin. Res. 34:141-147.

Druet, T., F. Jaffrézic, and V. Ducrocq. 2005. Estimation of genetic parameters for test day records of dairy traits in the first 3 lactations. Genet. Sel. Evol. 37:257-271.

FAOSTAT. 2006. Census and milk production data. http://faostat. fao.org/site/569/ Accessed Nov. 2007.

Foulley, J. L., and C. Robert-Granié. 2002. Basic tools for the statistical analysis of longitudinal data via mixed model. Course notes of precongress workshop. Proc. 7th World Congress on Genetics Applied to Livestock Production, Aug. 18, Montpellier, France. INRA, Castanet-Tolosan, France.

Gilmour, A. R., B. R. Cullis, J. Welham, and R. Thompson. 2000. ASREML Reference Manual. NSW Agric. Biom. Bull. NSW Agriculture, Orange, New South Wales, Australia.

Gipson, T. A., and M. Grossman. 1990. Lactation curves in dairy goats: A review. Small Rumin. Res. 3:383-396.

Ilahi, H., E. Manfredi, P. Chastin, F. Monod, J. M. Elsen, and P. Le Roy. 2000. Genetic variability in milking speed of dairy goats. Genet. Res. 75:315-319.
Jamrozik, J., and L. R. Schaeffer. 1997. Estimates of genetic parameters for a test day model with random regression for production of first lactation. J. Dairy Sci. 80:762-770.

Jamrozik, J., L. R. Schaeffer, and J. C. M. Dekkers. 1997. Genetic evaluation of dairy cattle using test day yields and random regression model. J. Dairy Sci. 80:1217-1226.

Kirkpatrick, M., W. G. Hill, and R. Thompson. 1994. Estimating the covariance structure of traits during growth and ageing, illustrated with lactation in dairy cattle. Genet. Res. 64:57-69.

Kirkpatrick, M., D. Lofsvold, and M. Bulmer. 1990. Analysis of the inheritance, selection and evolution of growth trajectories. Genetics 124:979-993.

Kominakis, A., E. Rogdakis, C. Vasiloudis, and O. Liaskos. 2000. Genetic and environmental sources of variation of milk yield of Skopelos dairy goats. Small Rumin. Res. 36:1-5.

Kominakis, A., M. Volanis, and E. Rogdakis. 2001. Genetic modeling of test day records in dairy sheep using orthogonal Legendre polynomial. Small Rumin. Res. 39:209-217.

Lopez Romero, P., and M. J. Carabaño. 2003. Comparing alternative random regression models to analyze first lactation daily milk yield data in Holstein Friesian cattle. Livest. Prod. Sci. 82:81-96.

Muller, C. J. C., S. W. P. Cloete, and S. J. Schoeman. 2002. Estimation of genetic parameters for milk yield and milk composition of South African Saanen goats. In Proc. 7th World Congress on Genetics Applied to Livestock Production, Montpellier, France. Communication 01-52. CD ROM. INRA, Castanet-Tolosan, France.

Olivier, J. J., S. W. P. Cloete, S. J. Schoeman, and C. J. C. Muller. 2005. Performance testing and recording in meat and dairy goats. Small Rumin. Res. 60:83-93.

Ptak, E., and L. R. Schaeffer. 1993. Use of test day yields for genetic evaluation in dairy sires and cows. Livest. Prod. Sci. 34:23-34.

Rabasco, A., J. M. Serradilla, J. A. Padilla, and A. Serrano. 1993. Genetic and non-genetic factors of variation and heritability of milk yield and quality in the Verata breed of goats. Small Rumin. Res. 11:151-161.

Rekaya, R., M. J. Carabaño, and M. A. Toro. 1999. Use of test day yields for the genetic evaluation of production traits in HolsteinFriesian cattle. Livest. Prod. Sci. 57:203-217.

Sarmento, J. L. R., J. C. R. Filho, L. G. de Albuquerque, P. S. Lopes, and M. T. Rodriguez. 2006. Genetic evaluation of Alpine goats using test day milk yield. Rev. Brasil. Zootec. 35:443-451.

Schaeffer, L. R. 2002. Dairy cattle test day model: A case study. Pages 233 246 in Intellectual Property Rights in Animal Breeding. M. Rothschild and S. Newman, ed. CAB International, Wallingford, UK.

Schaeffer, L. R. 2004. Application of random regression models in animal breeding. Livest. Prod. Sci. 86:35-45.

Schaeffer, L. R., and J. C. M. Dekkers. 1994. Random regressions in animal models for test-day production in dairy cattle. Pages $443-$ 446 in Proc. 5th World Congress of Genetics Applied to Livestock Production, Guelph, Ontario, Canada. Vol. XVIII. University of Guelph, Ontario, Canada.

Schaeffer, L. R., and J. Jamrozik. 2008. Random regression models: A longitudinal perspective. J. Anim. Breed. Genet. 125:145-146.

Serradilla, J. M. 2008. Objetivos, organización y factores limitantes de los programas de selección de las razas autóctonas en España. Información Técnica Económica Agraria 104:117-141.

Serrano, M., E. Ugarte, J. J. Jurado, M. D. Pérez-Guzmán, and A. Legarra. 2001. Test day models and genetic parameters in Latxa and Manchega dairy ewes. Livest. Prod. Sci. 67:253-264.

Valencia, M., J. Dobler, and H. H. Montaldo. 2007. Technical note: Genetic and phenotypic parameters for lactation traits in a flock of Saanen goats in Mexico. Small Rumin. Res. 68:318-322.

Zumbach, B., K. J. Peters, R. Emmerling, and J. Solkner. 2004. Development of a test day model for milk sheep and goats under unfavorable structure conditions in Germany. Abstract no. 555 in Proc. 55th Annual Meeting of EAAP, Bled, Slovenia. Wageningen Academic Publishers. Wageningen. the Netherlands.

Zumbach, B., S. Tsuruta, I. Misztal, and K. J. Peters. 2008. Use of test day model for dairy goat milk yield across lactation in Germany. J. Anim. Breed. Genet. 125:160-167. 